\title{
A Socioeducational Intervention about Parental Attitudes in Grassroots Football and Its Effects
}

\author{
Pere Palou Sampol, David Pulido Salas *(i), Pere A. Borràs Rotger and \\ Francisco J. Ponseti Verdaguer \\ GICAFE (Grup d'Investigació en Ciències de l'Activitat Física i l'Esport), University of the Balearic Islands; \\ 07122 Palma de Mallorca, Spain \\ * Correspondence: david.pulido@uib.es; Tel.: +34-662-220-933
}

Received: 25 May 2019; Accepted: 21 June 2019; Published: 26 June 2019

\begin{abstract}
Despite the importance and usefulness of previous observational methodology investigations' outcomes, there is no evidence about the creation or evaluation of a socioeducational intervention for parents in sport. Therefore, researchers do not have the possibility to apply a socioeducational intervention to their parental observations. This investigation was focused on the effects of the application of a socioeducational intervention with parents of 12 football teams in the U-15 years category in the Balearic Islands (Spain) during the 2016-17 season. Furthermore, six teams formed the control group (CG) and six constituted the experimental group (EG). This research was divided into three phases: (1) pre-test, (2) socioeducational intervention, and (3) post-test. The 12 matches recorded during the first phase and the 12 matches recorded during the third phase were observed and coded by trained observers using LINCE and POISE (parents' observation instrument at sport events). Results showed a decrease in negative comments and an increase in positive comments during the matches, confirming the socioeducational intervention performed with that aim. This study suggests that the present socioeducational intervention demonstrates improvements on parental attitudes in grassroot football and, due to this reason, we encourage authors to use it and provide feedback.
\end{abstract}

Keywords: grassroots football; parental observation; parental behavior; observational instrument; socioeducational intervention

\section{Introduction}

Organized youth sport programs provide enjoyment and regular physical activity for millions of children every year in many different countries around the world. The participation of adults allows us to have access to these opportunities, especially through the collaboration of parents [1]. At present, many parents are actively involved in youth sport, transmitting appropriate information to their children concerning all the possibilities they have in the sportive ambit, signing their children up to be part of an organized club, acquiring sportive equipment, paying league or federation fees, and providing transport to the different football fields [2]. Furthermore, some parents play also different roles inside their organized clubs as coaches, assistants, referees, and administrators [2].

Hence, it must be affirmed that children are able to participate in organized sport activities thanks to their parents' support [3]. In other words, parents become crucial for the formation of personal characteristics of youth athletes [4]. Due to the importance of parents in their children's lives, investigators have been focused on the involvement of parents in youth sport for decades [2,3,5-10].

Recently, researchers have been interested in parent-spectators' behaviors during youth sport events [8,11-13]. Concretely, Gould, Lauer, Rolo, Jannes and Pennisi [14] identified that contemporary society has tended to highlight those extreme bad behavior cases from parents, which negatively affect their children's sport experience. In the same vein, it is relevant to mention the reinforcement 
through different anecdotes published in the popular press about the perception of the control parent's loss in grassroots sports [1]. In fact, some authors have performed research from the stands, such as the authors of [15], who analyzed parent-spectators' behavior during grassroots hockey matches. These authors found that the most notorious comments were positive, and that the negative ones were directed to the referee [16]. Omli and LaVoi [12] carried out similar findings in grassroot football, pointing that parents shouted at their sons only moderately [16]. In addition, Holt, Tamminen, Black, Sehn and Wall [17] confirmed that approximately 35\% of comments performed by parent-spectators were related to supporting their children, while $15 \%$ were negative comments [16].

Nevertheless, there is evidence of other investigations which showed parental comments aimed to support their sons' aggressive tactics, to underline the importance of winning, and to scold those youth athletes who made mistakes [18]. In the same line, Shields, Bredemeier, LaVoi and Power [13] pointed that $14 \%$ of parents involved in grassroots sport admit that they have shouted or argued with referees; $13 \%$ of them affirm that they have criticized with anger the way their sons were playing on the pitch; and $15 \%$ of young athletes confirm that they have suffered angry behaviors from their own parents. Likewise, Turman [19] and Gould, Lauer, Rolo, Jannes and Pennisi [20] have also picked up negative experiences of parents in grassroots sport. Turman [19] confirmed that parents often gave all kinds of rewards to their sons to supply their limited involvement; and Gould et al. [20] affirmed that some parents usually offer money to their children to incentivize them in order to achieve a better sportive performance.

Hitherto, although not all studies made on parental behavior in grassroots sport show excessive negative comments during their sons' matches, there has been a significant number of technical instructions and negative reinforcements carried out from the stands that should be enough to be concerned about it. Fiore [21] added that the notorious increase of youth athletes within organized sport, associated to difficulties in regulating adults' attitudes involved in grassroots sport, could be the real problem which federated leagues face today.

Therefore, the purpose of this study is to determine the effects of a socioeducational intervention about parental attitudes in grassroots football. From this perspective, Anguera and Hernández [22] pointed that the best methodology to analyze the sport, physical activity in its context or its quotidian dynamic is the observational methodology. The main aim of the present investigation was directly related to the observational methodology, which defines its objectives, data collection, data management, and data analysis [23]. The study was conducted in a Spain context, which may provide data that could be used in possible cross-cultural analyses.

\section{Materials and Methods}

\subsection{Sample}

This investigation involved the participation of parent-spectators of 12 football clubs, which belonged to the U-15 years category in the Balearic Islands (Spain). Moreover, it is important to underline that all football clubs that participated were chosen randomly, due to one of the main purposes of the research being to extrapolate the obtained conclusions and results to all kind of sportive clubs.

\subsection{Instruments}

\subsubsection{Pre-Test}

The 12 matches recorded during the first phase were observed and coded by trained observers using LINCE [24] recording software and POISE (parents' observation instrument at sport events) [25].

LINCE (Barcelona, Spain) [24] is a software which provides observational computerized procedures in observation methodology that streamline the register of game actions or comments from the stands during the visualization of different matches' recordings on the same laptop screen. LINCE also allows 
codifying game actions or comments simultaneously, to verify the control of the data quality of the observers and to export the obtained results to other computer programs for further analysis [26].

POISE (United States) [25] is an instrument which was initially designed by Graham, Ratliffe, Faucette, Salter and Walley [27] for recording spectators' behavior in sport events. Afterwards, Randall and McKenzie [28] adopted the same instrument for recording the behavior carried out by adult spectators in grassroots football. Finally, Kidman and McKenzie [25] adopted this instrument and developed POISE (parents' observation instrument at sport events), which is able to record and analyze the nature of parental comments in their children's sport events.

Lastly, it is relevant to note that all football matches' recordings were created using the camcorder Toshiba Camileo X-200.

\subsubsection{Socioeducational Intervention}

Instruments used in this phase could be divided into two important sub-phases: (1) formation and (2) diffusion.

Referring to the formative sub-phase, it has to be said that the main resources were a projector screen, a projector, a laptop, a PowerPoint presentation, a montage video about parents' comments, and an extension cable.

On the other hand, thanks in part to the local Government, different material resources were used in the diffusion sub-phase. These instruments were: information leaflets, posters which summarized a decalogue of good manners to parents, spectators, coaches, and athletes, and fair play cards, which reminded parents their duty to be well-behaved in their children's sportive ambit.

\subsubsection{Post-Test}

In line with the pre-test, the 12 matches recorded during the third phase were observed and coded by trained observers using LINCE [24] recording software and POISE (parents' observation instrument at sport events) [25].

Furthermore, it must be mentioned that all football matches' recordings were created using the camcorder Toshiba Camileo X-200.

\subsection{Procedure}

\subsubsection{Pre-test}

Referring to the baseline establishment, it is important to underline that this research analyzed conducts and behaviors in humans, and for this reason, it was also accomplished in accordance with ethical principles of respect to the human dignity, confidentiality and nondiscrimination. Thus, the study was approved by the ethics committee of the University of the Balearic Islands (UIB) and conducted in accordance with Helsinki's Declaration of 1975 reviewed in 2000.

Furthermore, the permission to carry out the investigation was given by Govern de les Illes Balears (Government of the Balearic Islands) (Spain) through its project Posam Valors a l'Esport (Values in Sport). Additionally, the department of Physical Education and Sport of the University of the Balearic Islands (UIB) contacted the Balearic Islands Football Federation (FFIB) in order to obtain the entity and its football clubs' permissions.

Afterwards, researchers started with the analysis of the behaviors and conducts of parents in their children's football matches. That analysis was carried out through 12 observations using an observational instrument called the parents' observation instrument at sport events (POISE) [25], executing one recording per team. It has to be mentioned that $16 \mathrm{~h}$ were necessary to complete the observation from the stands, due to each match of U-15 category of the Balearic Islands (Spain) lasting $80 \mathrm{~min}$ divided into two halves of 40 each. One of the researchers was in all matches, because he had to record all of them using a camcorder. It is necessary to clarify that the researcher only recorded the football matches, and that the comments made by parent-spectators were registered by the sound. 
On the other hand, it must be added that if any father, mother or spectators had any kind of problem with the presence of the camcorder, the researcher reminded them of the main aim of the present investigation. Furthermore, the researcher had the possibility to show them the signed agreement by the local government and the University of the Balearic Islands, which allowed him to carry out scientific and technical actions during the 2016/2017 season.

As regards the recordings, the researcher was cautious, positioning himself between both clubs' supporters, always depending on the team that should be registered. In the first matches, it was not easy, due to the researcher and parents not knowing each other. For this reason, the researcher always arrived around 15 min earlier than the beginning of the match to identify the place where parents of both teams would be seated.

\subsubsection{Socioeducational Intervention}

In the second phase of this research, the socioeducational intervention with parents took place. This intervention is divided into two sub-phases: (1) formation and (2) diffusion.

Referring to the formative phase, it is crucial to highlight that the experimental group of parents is formed by 6 of the 12 analyzed teams. It is important to emphasize that in the formative phase, parents of the experimental group were cited in their sport facilities with the goal of knowing and acquiring a series of guidelines during the sport events. That formation was carried out for up to $40 \mathrm{~min}$ for each of the six experimental groups. The formative sessions were organized into six sections: (1) information about parental attitudes in grassroot sports of the local government called Values in Sport; (2) school-age sport goals; (3) motivation from the stands; (4) communication styles; (5) good-spectator guidelines; and (6) video of comments from the stands.

Section 1: Values in Sport. Within the first section, parents could internalize the main aims of the local government project called Posam Valors a l'Esport (Values in Sport), which is divided into three stages: baseline establishment where the observation of 12 matches is performed and the administration of questionnaires for parents and youth players alike; the socioeducational intervention with parents where the fair play counseling session takes place, as well as the delivery of information leaflets, fair play posters, and fair play cards; and, lastly, the intervention evaluation which is performed through the observation of 12 matches and the administration of questionnaires for parents.

Section 2: Sport aims in scholar age. In the present section of the formative session, the main aims of the school age sport were transmitted to parents. Such objectives are: physical, which pretend to enhance the physical fitness and condition of young athletes; sportive, to learn, improve, and perfect sport technical aptitudes; psychological, to learn how to cooperate and compete sportively and fairly, respecting other teams and sport rules, and social, which pretend to establish new friendships within the sportive ambit.

Section 3: Motivation from the stands. In the third section of the formative session, parents were informed about two types of motivational orientation followed by parents in sport. The first motivational slope is focused on egocentric conducts, which is based on results and the comparison with the rest; differently, the second slope is focused on mastery, individual progress, and skills enhancement. Thus, parents can identify the practical application of both motivational orientations with real comments performed by parents to their own children.

Section 4: Communication styles. In the fourth section of the formative session, parents acquired various action guidelines to improve the communicative styles with their sons in the social-sportive ambit. On the one hand, positive reinforcement and respectful comments are identified as positive communication styles. It is worth highlighting that parents can visualize an immediate practical application of said contents with examples of their own comments, which were registered in different matches. On the other hand, aggressive comments, ironic, and derogatory comments were identified as negative communication styles.

Section 5: Good-spectator guidelines. In this penultimate section, good-practice guidelines were shown to parents, aiming the assistants to influence their children, positively based on the next aspects: 
- Do not put the sport competition's results before the training process of their children;

- Do not create tension and/or false expectations before the match;

- Do not introduce technical information from the stands while young players are competing, because we would be playing the coach team's role;

- Support players after a match independently of the obtained score;

- Recognize the superiority of the opponent when the awaited results are not obtained.

All these premises are essential to make youth players grow up and develop as people and athletes that focus on the sport values. Parents must bear in mind that what they say and do during a training session, pre-match, match or post-match can influence their children's memory and opinion positively or negatively.

Section 6: Video of comments from the stands. In the last section of the formative phase, parents were able to identify their own comments and, hence, the teaching-learning process of the different contents dealt with previously. Using this video montage, which included various game actions and parental comments from the stands, the researcher stopped the media player each time that a comment was made. Once the type of comment was identified, it was analyzed whether that kind of comment was appropriate enough for the real moment in which it was emitted.

On the other hand, it is also noteworthy that the diffusive phase of the socioeducational intervention with parents had the support of a set of resources provided by Govern de les Illes Balears (Government of the Balearic Islands): Fair play information leaflets, good-spectator guideline, and fair play information cards.

Moreover, it must be mentioned that information leaflets were delivered at the end of the formative session with parents. The purpose of this measure was to sum up all the different sections of the project of Values in Sport.

Referring to the good-spectator guidelines, it is necessary to note that they contained aspects that should be carried out by the different socioeducational agents in sport. Concretely, these guidelines were hung on strategic zones of the analyzed sports facilities, as long as the clubs' leaders gave us permission. These resources were hung to let the spectators of a training session or a match appreciate which way they must behave in that club.

Finally, it must be highlighted that in the next league match, just after the formative session with parents, both parents and spectators received fair play information cards, which were used as reminders of the formative session contents.

\subsubsection{Post-Test}

The third phase referred to the fieldwork of the present investigation evinced the evaluation of the socioeducational intervention performed with parents. In this final phase of the study, the analysis of the behavior and conducts of those parent-spectators who were analyzed during the baseline of the present research took place. Furthermore, it must be pointed out that in this section, parent-spectators were analyzed in 12 matches, which means a match per team. The previously mentioned analysis was carried out through the observational instrument, parents' observation instrument at sport events (POISE) [25]. It is relevant to confirm that $16 \mathrm{~h}$ were necessary to complete the observation from the stands, due to all football matches of the U-15 category in the Balearic Islands (Spain) lasting $80 \mathrm{~min}$ divided into two halves of 40 each.

One of the researchers of the investigation was in all the mentioned matches, because he recorded them using a camcorder. It is necessary to clarify that the researcher only recorded the football matches, and parents' comments were registered by the sound. On the other hand, it must be added that if any father, mother or spectator had any kind of problem with the presence of the camcorder, the researcher reminded them of the main aim of the present investigation, as had already occurred during the baseline phase. 
As had already happened on the pre-test phase, the researcher was cautious again, positioning himself between both clubs' supporters, always depending on the team that should be registered. Nevertheless, unlike the first phase of the present investigation, the researcher already knew most of the parents and the sports facilities of the different analyzed football clubs and, therefore, it was easier to identify them.

Moreover, it must be added that once all the phases of the investigation were finished, two independent observers analyzed one by one all the recorded matches through a camcorder. This part of the investigation was performed to register the different comments emitted by the 12 analyzed clubs' parents. It is also noteworthy that this task lasted one hour per match, and the interobserver analysis was based on the parents' observation instrument at sport events (POISE) [25].

Furthermore, it must be emphasized that these records were defined through the abovementioned instrument, which divided all the comments into positive, neutral, and negative. The observers determined the number of comments registered by the LINCE software [24] (Figure 1), which allowed exporting the outcomes to EXCEL software to complete the final recount of the different types of comments.

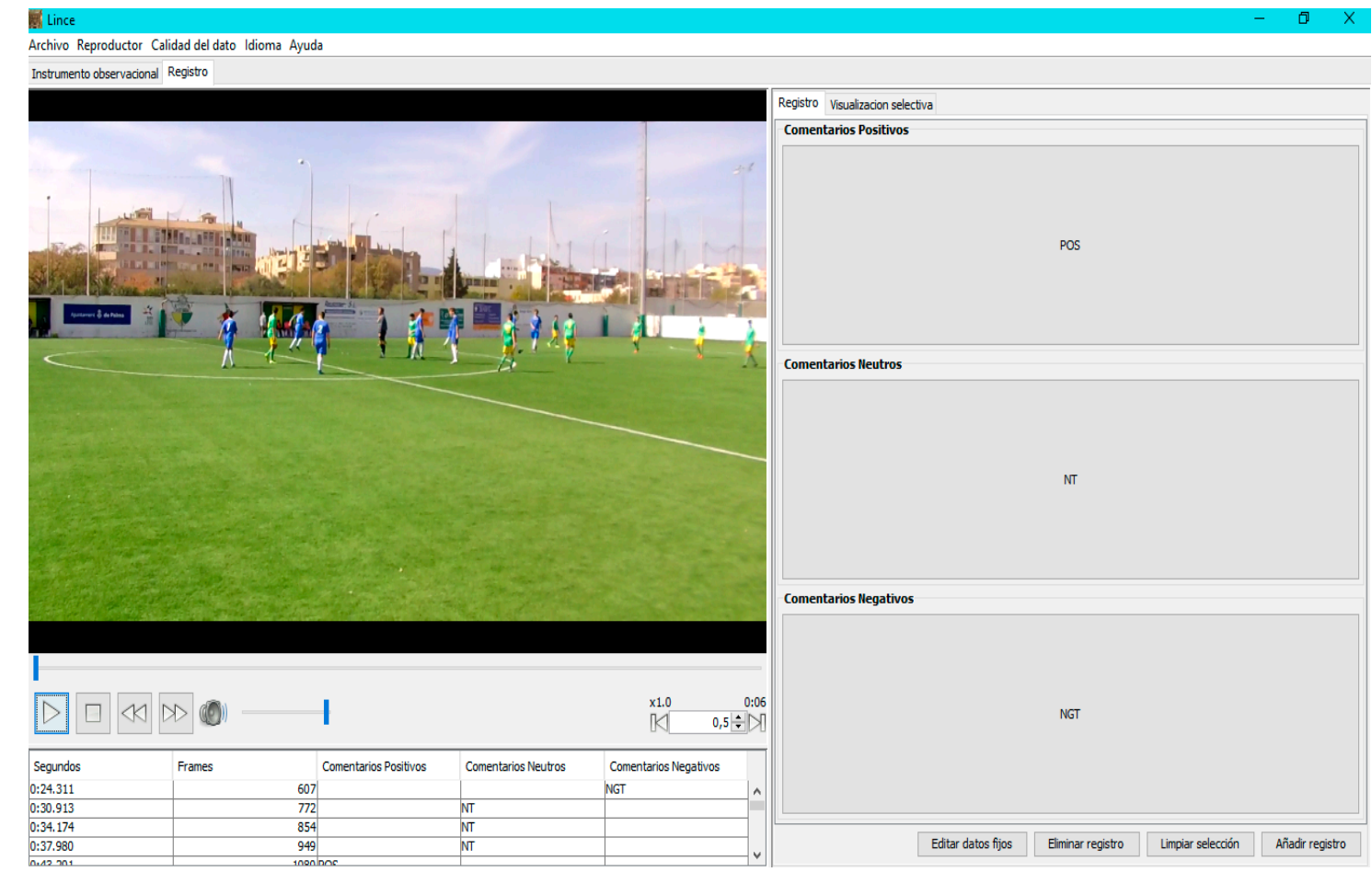

Figure 1. Recording instrument LINCE [24].

Additionally, in Figure 2, the timetable that researchers used to develop the different phases of the present investigation is observed. 


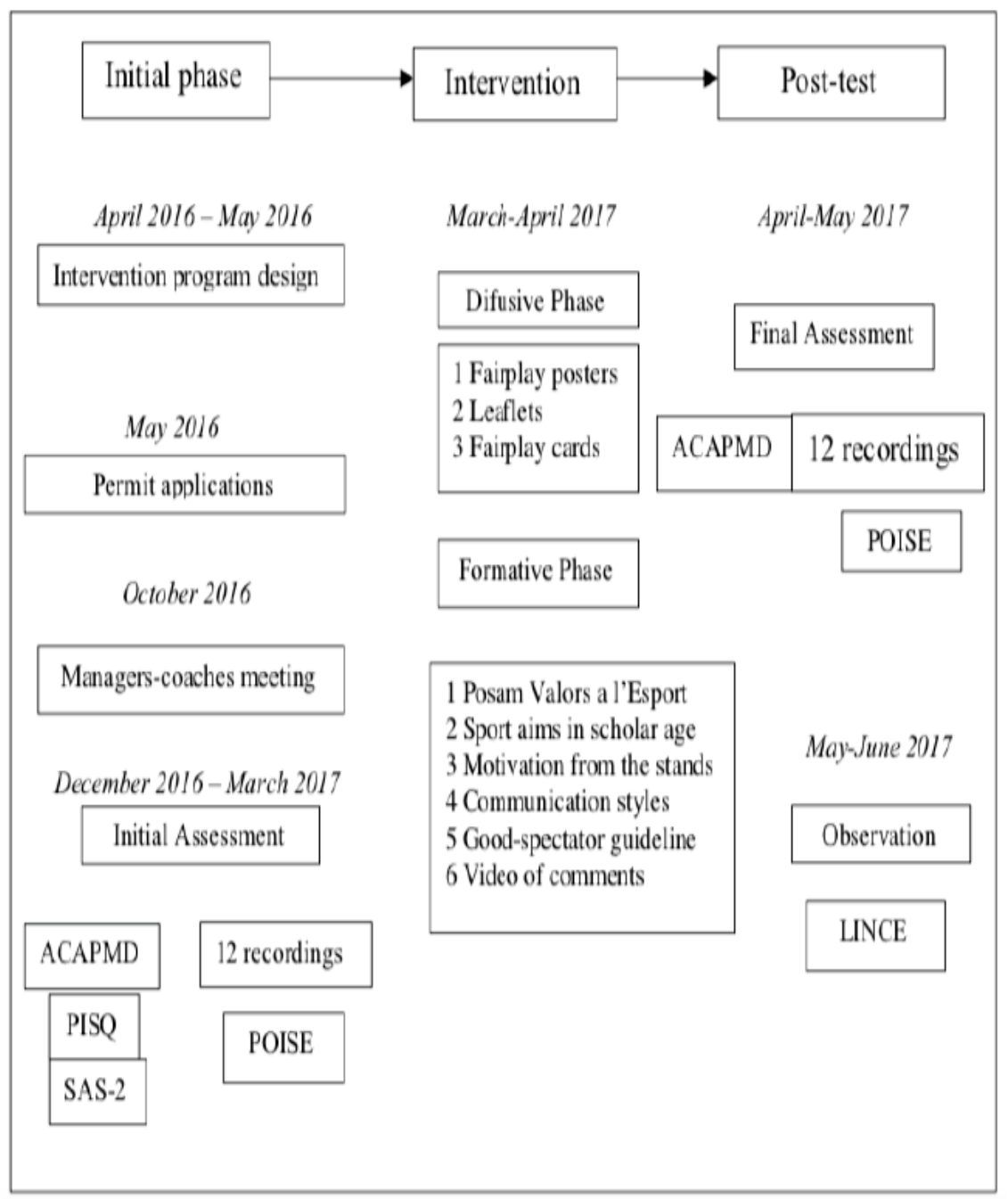

Figure 2. Timetable.

\subsection{Statistical Analysis}

The effects of the socioeducational intervention about parental attitudes in grassroots football, comparing the baseline and post-test's outcomes, were analyzed using $t$-test. Furthermore, it must be mentioned that a descriptive analysis was executed to define the mean of each type of comment. The data analysis was conducted using IBM SPSS (New York, United States, Version 21.0) and a statistical significance of $5 \%(p<0.05)$ was defined.

\section{Results}

Before the contrast of means, the assumptions of normality (K-S test) and equality of variance (Levene test) were verified, so that parametric tests were carried out when these assumptions were fulfilled.

Table 1 shows that the experimental group reduced the mean of negative comments from 16.61 in pre-test to 9.49 in post-test, defining a significant improvement. 
Table 1. Mean of comments in pre-test and post-test by groups and $t$-test.

\begin{tabular}{ccccccc}
\hline & \multicolumn{3}{c}{ Experimental Group } & \multicolumn{3}{c}{ Control Group } \\
& Pre & Post & Sign. & Pre & Post & Sign. \\
\hline Positives & 20.26 & 23.00 & $\mathrm{t}=0.628 p=0.558$ & 19.23 & 32.05 & $\mathrm{t}=-2.562 p=0.051$ \\
Neutral & 63.12 & 67.51 & $\mathrm{t}=0.820 p=0.450$ & 57.23 & 50.64 & $\mathrm{t}=-1.068 p=0.335$ \\
Negatives & 16.61 & 9.49 & $\mathrm{t}=-3.145 p=0.026$ & 23.54 & 17.31 & $\mathrm{t}=-1.264 p=0.262$ \\
\hline
\end{tabular}

According to the results of the means test $(t=-3.145 ; p=0.026)$, statistically significant differences were detected between the mean of negatives comments of pre- and post-test in the experimental group. In addition, the correlation between the mean of negatives comments of pre- and post-test in the experimental group was statistically significant $(\mathrm{rxy}=0.62, p=0.031)$. On the other hand, the value of effect size correlation was large $\left(\mathrm{r}_{Y \lambda}=0.815\right)$, according to [29] and [30].

Nonetheless, significant differences were not observed within the category of positive comments performed by the experimental group. Hitherto, an enhancement about pre-values (20.26) and post-values (23) is observed; these have not represented significant changes.

Referring to the control group, it must be highlighted that there are no significant changes in any of the three analyzed types of comments; however, the average of positive comments performed during post-test (32.05) rather than pre-test (19.23) increased notably.

Furthermore, some real examples of parental comments from the stands have been included within Table 2. This categorization of comments follows the type of comments recognized by POISE [25].

Table 2. Comments performed by parents in football matches.

\begin{tabular}{|c|c|c|}
\hline Positives & Neutral & Negatives \\
\hline $\begin{array}{l}\text { “Come on, guys! It is possible! We } \\
\text { can ... until the last minute” } \\
\text { “Good rehearsed game!" } \\
\text { “There are } 80 \text { min, come on, boys!" } \\
\text { "Two occasions he has had, and he } \\
\text { has caught them all!” } \\
\text { “Nice goalkeeper, nice!” } \\
\text { “Very good, buddy!” } \\
\text { "Well done, Marc + Applauses" } \\
\text { "Great, boys!” }\end{array}$ & $\begin{array}{l}\text { "Oh my God ... It is so cold today" } \\
\text { "I am allergic, and it is still active ... " } \\
\text { "Reiterated silences" } \\
\text { "It is raining ... Look how the sky } \\
\text { looks now" } \\
\text { "I do not mind" } \\
\text { "This zone is so fucking great" } \\
\text { "I tell you this, because I am interested } \\
\text { in this job" } \\
\text { "Is it necessary to carry on your license } \\
\text { to do it?" } \\
\text { "The thing is that she called us, and } \\
\text { they gave us the tickets" } \\
\text { "Because were awaken from 6am and } \\
\text { we went there" }\end{array}$ & $\begin{array}{l}\text { "Enough! It has been the opposite, } \\
\text { referee!" } \\
\text { "Eh, guy! Are you subnormal?" } \\
\text { "Are you colorblind? You think all of } \\
\text { them are red!" } \\
\text { "If you do not score, you will not have } \\
\text { dinner tonight" } \\
\text { "Fool! Fool! Fool!" } \\
\text { "You will not win anything, idiots!" } \\
\text { "There is a case, a case! We prefer a chest, } \\
\text { because the case is not enough" }\end{array}$ \\
\hline
\end{tabular}

\section{Discussion}

The purpose of this study was to determine the effects of a socioeducational intervention about parental attitudes in grassroots football. It is important to highlight that the main aim of the present investigation was directly related to the observational methodology which defines its objectives, data collection, data management, and data analysis [23].

Now, considering the above cited objective, it becomes relevant to mention that according to the obtained results, the positive influence of the present socioeducational intervention with parents can be confirmed. Hence, the results showed that the experimental group experienced a reduction of 7.12 of negative comments from the baseline to post-test, and they also experienced an enhancement of 2.74 of positive comments. The results also showed that the control group increased by 12.82 the number of positive comments from the baseline to post-test. It is relevant to mention that no concrete scientific literature has been found which analyzes the effects of a socioeducational intervention considering the mean and type of comments performed by parents from the baseline to post-test. For this reason, it is not possible to compare the obtained data with other investigations; although it must be mentioned 
that the most notorious type of comments of the experimental group, both pre-test and post-test, were neutral comments followed by positive and negative comments. Referring to the control group, it must be pointed out that the most notorious type of comments during the pre-test was neutral comments, followed by negative and positive comments; nonetheless, during the post-test, the most abundant type of comments was neutral comments, followed by positive and negative. These results differ from those found in the study by Blom and Drane [31], who observed that positive comments were the most abundant, followed by negative and neutral comments. Likewise, it must be emphasized that Kidman, McKenzie and McKenzie [32] showed that negative behaviors performed by parents from the stands constituted a $45.4 \%$ of total comments they observed in grassroots football. Hitherto, these values are above the obtained outcomes of the present study referring to negative comments. It is important to recognize that most investigations about parental participation in sports of their sons always implicate the existence of any grade of pressure, negative comments or other negative conducts from the stands, which could produce negative psychosocial effects on their children [33].

In conclusion, the main findings of the present investigation indicate that, on the one hand, the socioeducational intervention carried out with parents was performed successfully because it produced significant positive outcomes on parental comments. This fact is noticeable in the significant decrease of the experimental group's negative comments, which were reduced from 16.61 in the pre-test to 9.49 in the post-test.

On the other hand, despite having no significant outcomes on the experimental group's positive comments, it is important to underline that an enhancement has been found in this regard from 20.26 in the pre-test to 23 in the post-test.

These results reinforce the need to promote parental acceptance about their interventions from the stands, which should be based on positive reinforcement and respect towards all the involved people in sport. This fact is vital if the main goal of the sporting environment is that young athletes grow through values in sport and increase their self-esteem levels.

Considering the obtained outcomes, the importance and novelty of the present investigation is highlighted. Likewise, it is relevant to emphasize the main strengths of the study, such as the feasibility of the socioeducational intervention with parents, the observational design for observing and coding pre- and post-tests' matches, and that there were no exclusion conditions to carry out the socioeducational intervention with parents.

This study also presents some limitations. One of them is the category, which was analyzed because it does not allow a wider intergroup comparison, due to it being uniquely based on the U-15 years category. Another important limitation that must be underlined is that female teams have not been included in the sample. Moreover, some participant characteristics such as age, socioeconomic situation, gender or level of education were not analyzed.

On balance, the need to deeply research the present field to obtain more objective conclusions in this regard and to compare these outcomes with other researchers' investigations is reflected.

Hence, it is definitely positive to found projects based on values in sport, such as Posam Valors a l'Esport (Balearic Islands-Spain), El Respeto Gana (Murcia-Spain) or Vamos Juntos (Murcia-Spain).

Author Contributions: Conceptualization, D.P.S., F.J.P.V., and P.A.B.R.; Data curation, D.P.S.; Formal analysis, D.P.S., P.P.S., P.A.B.R., and F.J.P.V.; Investigation, D.P.S.; Methodology, D.P.S., P.P.S., P.A.B.R., and F.J.P.V.; Software, D.P.S.; Supervision, D.P.S., and P.P.S.; Writing—original draft, D.P.S.; Writing—review and editing, D.P.S., P.P.S., P.A.B.R., and F.J.P.V.

Funding: This research was conducted, in part, thanks to a grant (Values in sport) from Conselleria de Transparència, Cultura i Esport. Govern de les Illes Balears (Government of the Balearic Islands) (Spain). Project number (06605).

Acknowledgments: We would like to thank all youth football players and parents who participated in our investigation.

Conflicts of Interest: The authors declare that the research was conducted in the absence of any commercial or financial relationships that could be construed as a potential conflict of interest. 


\section{References}

1. Omli, J.; LaVoi, N.M. Emotional experiences of youth sport parents I: Anger. J. Appl. Sport Psychol. 2012, 24, 10-25. [CrossRef]

2. Fredricks, J.A.; Eccles, J.S. Parental influences on youth involvement in sports. In Developmental Sport and Exercise Psychology: A Lifespan Perspective; Weiss, M.R., Ed.; Fitness Information Technology: Morgantown, WV, USA, 2004; pp. 145-164.

3. Lozano, D.; Camerino, O.; Hileno, R. Análisis del comportamiento táctico ofensivo en momentos críticos de juego en el alto rendimiento en balonmano: Un estudio Mixed Methods. Cuad. Psicol. Dep. 2016, 16, 151-160.

4. Pulido, D. Parental involvement in grassroots football: The opinions of parents and their children. J. Phys. Educ. Health 2018, 7, 31-37.

5. Cruz, J.; Boixadós, M.; Torregrosa, M.; Mimbrero, J. ¿Existe un deporte educativo?: Papel de las competiciones deportivas en el proceso de socialización del niño. Rev. Psicol. Dep. 1996, 5, 111-132.

6. Pallarés, J. Los agentes psicosociales como moduladores de la motivación en deportistas jóvenes orientados al rendimiento: Un modelo causal. Rev. Psicol. Dep. 1998, 7, 275-281.

7. Peiró, C. La teoría de las perspectivas de meta y la educación física: Un estudio sobre los climas motivacionales. Rev. Psychol. Soc. Apl. 1999, 9, 25-44.

8. Omli, J.; LaVoi, N.M.; Wiese-Bjornstal, D.M. Towards an understanding of parent spectator behavior at youth sport events. J. Youth Sports 2008, 3, 30-33.

9. Fraser-Thomas, J.; Côté, J. Understanding adolescents' positive and negative developmental experiences in sport. Sport Psychol. 2009, 23, 3-23. [CrossRef]

10. Pulido, D.; Borràs, P.A.; Ponseti, F.J. La influencia y actuación de los padres en el fútbol cadete. Sport TK 2019, 8, 51-56. [CrossRef]

11. Goldstein, J.D. A Motivational Model of "Sideline Rage" and Aggression in Parents of Youth Soccer Players. Paper Presented at the Meeting of the Association for the Advancement of Applied Sport Psychology, Vancouver, BC, Canada, 27 October 2005.

12. Omli, J.; LaVoi, N.M. Background anger in youth sport: A perfect storm? J. Sport Behav. 2009, 32, 242.

13. Shields, D.L.; Bredemeier, B.L.; LaVoi, N.M.; Power, F.C. The sport behavior of youth, parents, and coaches: The good, the bad, and the ugly. J. Res. Char. Educ. 2005, 3, 4.

14. Gould, D.; Lauer, L.; Rolo, C.; Jannes, C.; Pennisi, N. Understanding the role parents play in tennis success: A national survey of junior tennis coaches. Br. J. Sports Med. 2006, 40, 632-636. [CrossRef] [PubMed]

15. Bowker, A.; Boekhoven, B.; Nolan, A.; Bauhaus, S.; Glover, P.; Powell, T.; Taylor, S. Naturalistic observations of spectator behavior at youth hockey games. Sport Psychol. 2009, 23, 301-316. [CrossRef]

16. Elliott, S.; Drummond, M. The (limited) impact of sport policy on parental behaviour in youth sport: A qualitative inquiry in junior Australian football. Int. J. Sport Policy Polit. 2015, 7, 519-530. [CrossRef]

17. Holt, N.L.; Tamminen, K.A.; Black, D.E.; Sehn, Z.L.; Wall, M.P. Parental involvement in competitive youth sport settings. Psychol. Sport Exerc. 2008, 9, 663-685. [CrossRef]

18. Bean, C.N.; Jeffery-Tosoni, S.; Baker, J.; Fraser-Thomas, J. Negative parental behaviour in Canadian youth hockey: Expert insiders' perceptions and recommendations. Revue phénEPS/PHEnex, J. 2016, 7, 3.

19. Turman, P.D. Parental sport involvement: Parental influence to encourage young athlete continued sport participation. J. Fam. Comm. 2007, 7, 151-175. [CrossRef]

20. Gould, D.; Lauer, L.; Rolo, C.; Jannes, C.; Pennisi, N. The role of parents in tennis success: Focus group interviews with junior coaches. Sport Psychol. 2008, 22, 18-37. [CrossRef]

21. Fiore, D.K. Parental rage and violence in youth sports: How can we prevent "Soccer Moms" and "Hockey Dads" from interfering in youth sports and causing games to end in fistfights rather than handshakes? Villanova Sports Ent. Law J. 2003, 10, 103-129.

22. Anguera, M.T.; Hernández, A. Técnicas de análisis en estudios observacionales en ciencias del deporte. Cuad. Psicol. Dep. 2015, 15, 13-30. [CrossRef]

23. Anguera, M.T.; Blanco, A.; Hernández, A.; Losada, J.L. Diseños observacionales: Ajuste y aplicación en psicología del deporte. Cuad. Psicol. Dep. 2011, 11, 63-76.

24. Gabín, B.; Camerino, O.; Anguera, M.T.; Castañer, M. Lince: Multiplatform sport analysis software. Procedia 2012, 46, 4692-4694. [CrossRef] 
25. Kidman, L.; McKenzie, A. Parents' verbal comments at sport events. In Investing in Children, Primary Prevention Strategies: Proceedings of the Children's Issues Centre Inaugural Child and Family Policy Conference, Dunedin, New Zealand, 10-13 July 1996; Children's Issues Centre: Auckland, New Zealand, 1996; pp. 344-353.

26. Hernández, A.; Castellano, J.; Camerino, O.; Jonsson, G.; Blanco, A.; Lopes, A.; Anguera, M.T. Programas informáticos de registro, control de calidad del dato, y análisis de datos. Rev. Psicol. Dep. 2014, 23, 111-121.

27. Graham, G.; Ratliffe, T.; Faucette, N.; Salter, W.; Walley, P. Adult Spectator Verbal Behavior at Youth Sport Games: A Descriptive Analysis; Association Internationale des Ecoles Superieres d'education Physique: Boston, MA, USA, 1982.

28. Randall, L.; McKenzie, T.L. Spectator verbal behavior in organized youth soccer: A descriptive analysis. J. Sport Behav. 1987, 10, 200-211.

29. Rosenthal, R. Meta-Analytic Procedures for Social Research, rev. ed.; Sage: Newbury Park, CA, USA, 1991.

30. Cohen, J. Statistical Power Analysis for the Behavioral Sciences, 2nd ed.; LEA: Hillsdate, MI, USA, 1988.

31. Blom, L.C.; Drane, D. Parents' Sideline Comments: Exploring the Reality of a Growing Issue. Available online: http://www.athleticinsight.com (accessed on 26 June 2019).

32. Kidman, L.; McKenzie, A.; McKenzie, B. The nature and target of parents' comments during youth sport competitions. J. Sport Behav. 1999, 22, 54.

33. Bois, J.E.; Lalanne, J.; Delforge, C. The influence of parenting practices and parental presence on children's and adolescents' pre-competitive anxiety. J. Sports Sci. 2009, 27, 995-1005. [CrossRef] [PubMed]

(C) 2019 by the authors. Licensee MDPI, Basel, Switzerland. This article is an open access article distributed under the terms and conditions of the Creative Commons Attribution (CC BY) license (http://creativecommons.org/licenses/by/4.0/). 